\title{
Feasibility study of conventional, DVSP, and THD-based heat supply systems
}

\author{
D. $O$. Romanov ${ }^{1, *}$, and $Y . V$. Yavorovsky ${ }^{1}$ \\ ${ }^{1}$ National Research University "Moscow Power Engineering Institute", Moscow, Russia
}

\begin{abstract}
Thermohydraulic dispatcher (THD) can be widely used in district heating systems. Heat source is one of the possible places of its application. In this case, it is possible to achieve hydrodynamic separation of heat source and heat supply network. This paper deals with comparison of three types of heat substation connection to heat source: conventional system, DVSP system, THD-based system. The latter two have variable speed pumps instead of throttling valves. Based on electricity consumption and investment costs calculations, total discounted costs of three systems were estimated. In result, DVSP system is more beneficial, while conventional system and THD-based system have high operational and investment costs accordingly.
\end{abstract}

\section{Introduction}

Thermohydraulic dispatcher (THD) is a device of low hydraulic resistance allowing for hydrodynamic separation of circuits connected to it. THD properties, advantages and ways of application are considered in [17]. Application of THD for district heating systems can be beneficial in terms of electricity saving. Chinese researchers have found that application of hydraulic connector, the device with low differential pressure and similar to THD, along with variable speed pumps for district heating systems may lead to significant energy saving effect [8-14]. The goal of this paper is to compare three types of heat substation connection to heat source: conventional system (Figure 1), DVSP system proposed by Chinese researchers [8] (Figure 2), and the system with THD (Figure 3). Conventional system includes throttle valves, while two other systems have variable speed pumps and hydraulic connector or THD installed at heat source station. So, redundant available hydraulic head at nearest consumers is not created in DVSP and THD-based systems. Power consumption of three systems was estimated and economic calculations for Russian conditions were performed.

\section{Methods}

\subsection{Power consumption}

In order to determine hydraulic head and power consumption of pumps in three systems, Kirchhoff's laws were used. It was decided to consider the systems with just three consumers (heat substations) to make formulas and calculations simpler. Schemes and formulas below contain following parameters: $\mathrm{H}$ hydraulic head, $\mathrm{m} ; \mathrm{S}-$ hydraulic resistance, $\mathrm{m}^{*} \mathrm{~s}^{2 *} \mathrm{~m}^{-6} ; \mathrm{V}$ - volume flow rate, $\mathrm{m}^{3 *} \mathrm{~s}^{-1} ; \mathrm{N}$ - power of pump, W; $\rho-$ density, $\mathrm{kg}^{*} \mathrm{~m}^{-3} ; \mathrm{g}-$ gravitational acceleration, $\mathrm{m}^{*} \mathrm{~s}^{-2} ; \eta-$ coefficient of performance (COP) of pump.

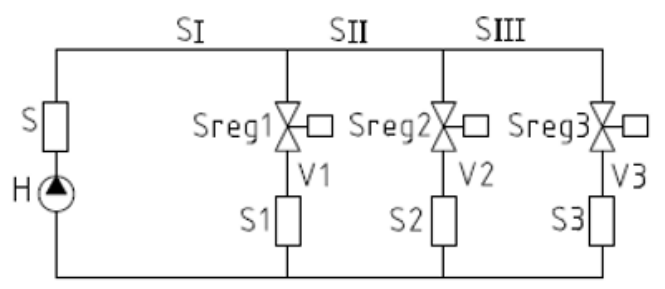

Fig. 1. Hydraulic scheme of conventional heat supply system.

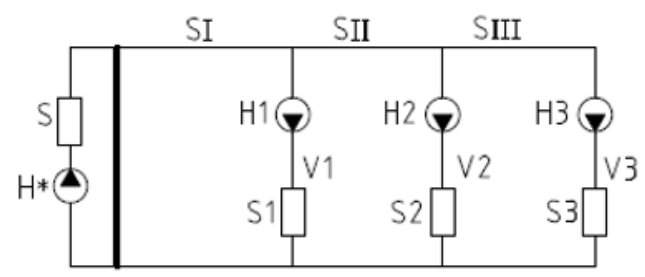

Fig. 2. Hydraulic scheme of DVSP system [8].

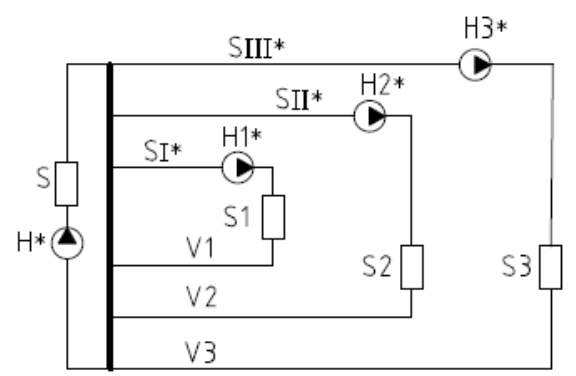

Fig. 3. Hydraulic scheme of THD-based heat supply system.

\footnotetext{
* Corresponding author: dimrom09@gmail.com
} 
Hydraulic head and power of pumps in conventional system are estimated by following equations:

$$
\begin{gathered}
H=\left(S+S_{I}\right) *\left(V_{1}+V_{2}+V_{3}\right)^{2}+ \\
+S_{I I} *\left(V_{2}+V_{3}\right)^{2}+\left(S_{I I}+S_{3}+S_{r e g 3}\right) * V_{3}{ }^{2} \\
N=\frac{H \cdot\left(V_{1}+V_{2}+V_{3}\right) \cdot \rho \cdot g}{\eta}
\end{gathered}
$$

Hydraulic head and power of pumps in DVSP system are estimated by following equations:

$$
\begin{gathered}
H_{*}=S *\left(V_{1}+V_{2}+V_{3}\right)^{2} \\
H_{1}=S_{I} *\left(V_{1}+V_{2}+V_{3}\right)^{2}+S_{1} * V_{1}^{2} \\
H_{2}=S_{I} *\left(V_{1}+V_{2}+V_{3}\right)^{2}+ \\
+S_{I I} *\left(V_{2}+V_{3}\right)^{2}+S_{2} * V_{2}{ }^{2} \\
H_{3}=S_{I} *\left(V_{1}+V_{2}+V_{3}\right)^{2}+ \\
+S_{I I} *\left(V_{2}+V_{3}\right)^{2}+\left(S_{I I}+S_{3}\right) * V_{3}{ }^{2} \\
N_{*}=\frac{H_{*} *\left(V_{1}+V_{2}+V_{3}\right) * \rho * g}{\eta} \\
N_{1}=\frac{H_{1} * V_{1} * \rho * g}{\eta} \\
N_{2}=\frac{H_{2} * V_{2} * \rho * g}{\eta} \\
N_{3}=\frac{H_{3} * V_{3} * \rho * g}{\eta} \\
N_{\text {sum }}=N_{*}+N_{1}+N_{2}+N_{3}
\end{gathered}
$$

Hydraulic head and power of pumps in the system with THD are estimated by following equations:

$$
\begin{aligned}
& H_{*}=S *\left(V_{1}+V_{2}+V_{3}\right)^{2} \\
& H_{1 *}=\left(S_{1 *}+S_{1}\right) * V_{1}{ }^{2} \\
& H_{2 *}=\left(S_{I I *}+S_{2}\right) * V_{2}{ }^{2} \\
& H_{3 *}=\left(S_{I I 1 *}+S_{3}\right) * V_{3}^{2} \\
& N_{*}=\frac{H_{*} *\left(V_{1}+V_{2}+V_{3}\right) * \rho * g}{\eta} \\
& N_{1 *}=\frac{H_{1} * V_{1} * \rho * g}{\eta} \\
& N_{2 *}=\frac{H_{2} * V_{2} * \rho * g}{\eta} \\
& N_{3 *}=\frac{H_{3} * V_{3} * \rho * g}{\eta} \\
& N_{\text {sum }}=N_{*}+N_{1} * N_{2 *}+N_{3} *
\end{aligned}
$$

Power consumption difference between conventional system and DVSP system is as follows:

$$
\begin{aligned}
& \Delta N_{\text {conv-dvsp }}=N-N_{\text {sum }}= \\
& \quad=\frac{\rho * g}{\eta}\left(S_{I I} *\left(V_{2}+V_{3}\right)^{2} * V_{1}+\right.
\end{aligned}
$$

$$
\begin{aligned}
& +S_{I I I} * V_{3}{ }^{2} *\left(V_{1}+V_{2}\right)+\left(S_{3}+S_{r e q 3}\right) * V_{3}{ }^{2} * \\
& \left.*\left(V_{1}+V_{2}\right)-S_{1} * V_{1}^{3}-S_{2} * V_{2}^{3}\right)
\end{aligned}
$$

Similar result was obtained in $[9,11]$. The first two summands represent pump power needed for pumping water to the consecutive consumers in conventional system. The third, fourth, and fifth summands together represent the difference between required hydraulic heads (in the form of pump power) at the last consumer and the preceding consumers. Moreover, the difference can be either negative or positive depending on consumers.

Power consumption difference between DVSP and THD-based system is as follows:

$$
\begin{aligned}
& \Delta N_{\text {dvsp-thd }}=N_{\text {sum }}-N_{\text {sum* }}= \\
& =\frac{\rho * g}{\eta}\left(\left(S_{I} *\left(V_{1}+V_{2}+V_{3}\right)^{3}-S_{l *} * V_{1}{ }^{3}\right)+\right. \\
& +\left(S_{I I} *\left(V_{2}+V_{3}\right)^{3}-S_{I I *} * V_{2}{ }^{3}\right)+ \\
& \left.+\left(S_{I I} * V_{3}{ }^{3}-S_{I I *} * V_{3}{ }^{3}\right)\right)
\end{aligned}
$$

It can be noticed that power consumption difference in formula (22) does not depend on pressure drop at consumers. Three summands in brackets represent pump power difference between DVSP system and THD-based system required to pump water through main lines.

Formula (22) can be modified using formulas (23) and (24).

$$
\begin{aligned}
& S=\frac{0.0894 \cdot k_{2}^{0,25} *\left(1+l_{2}\right)}{g * d^{5.25}} \\
& d=\sqrt{\frac{4 \cdot V}{\pi \cdot W}}
\end{aligned}
$$

where $k_{3}$ - coefficient of pipe equivalent roughness; $l$ - pipe length, $\mathrm{m} ; l_{3}-$ equivalent pipe length, $\mathrm{m} ; d-$ pipe diameter, $\mathrm{m} ; \mathrm{w}$ - velocity of heat carrier, $\mathrm{m} / \mathrm{s}$.

Then formula (22) can be written as:

$N_{\text {dvsp-thd }}=K *\left[\left(l_{l}+l_{l 3}\right) *\left(w_{1}^{\frac{21}{8}} *\left(V_{1}+V_{2}+V_{3}\right)^{\frac{3}{8}}-\right.\right.$ $\left.w_{I}^{\frac{21}{8}} * V_{1}^{\frac{3}{8}}-w_{H I}^{\frac{21}{8}} * V_{2}^{\frac{3}{8}}-w_{H I}^{\frac{21}{8}} * V_{3}^{\frac{3}{8}}\right)+\left(l_{H I}+l_{H I 3}\right) *$ $\left.\left(w_{11}^{\frac{21}{8}} *\left(V_{2}+V_{3}\right)^{\frac{3}{8}}-w_{11}^{\frac{21}{8}} * V_{2}^{\frac{3}{8}}-w_{l 1}^{\frac{21}{8}} * V_{3}^{\frac{3}{8}}\right)\right]$

Or in a generic form for $\mathrm{N}$ heat substations formula (25) can be written as:

$$
\begin{aligned}
& \Delta N_{d v s p-t h d}=K * \sum_{i=1}^{N-1}\left[( l _ { i } + l _ { i 3 } ) * \left(w_{i}^{2,625} *\right.\right. \\
& \left.\left.\left(\sum_{j=i}^{N} V_{j}\right)^{0,375}-\sum_{j=i}^{N} w_{j}^{2,625} * V_{j}^{0,375}\right)\right]
\end{aligned}
$$

where $K=0,0474 * \frac{k_{2} * \rho}{\eta}, \mathrm{kg} / \mathrm{m}^{2.75}$.

To estimate the change of pump power under change of heat carrier velocities partial derivatives were obtained and analyzed: 
Trenchless pipe laying, polyurethane foam insulation

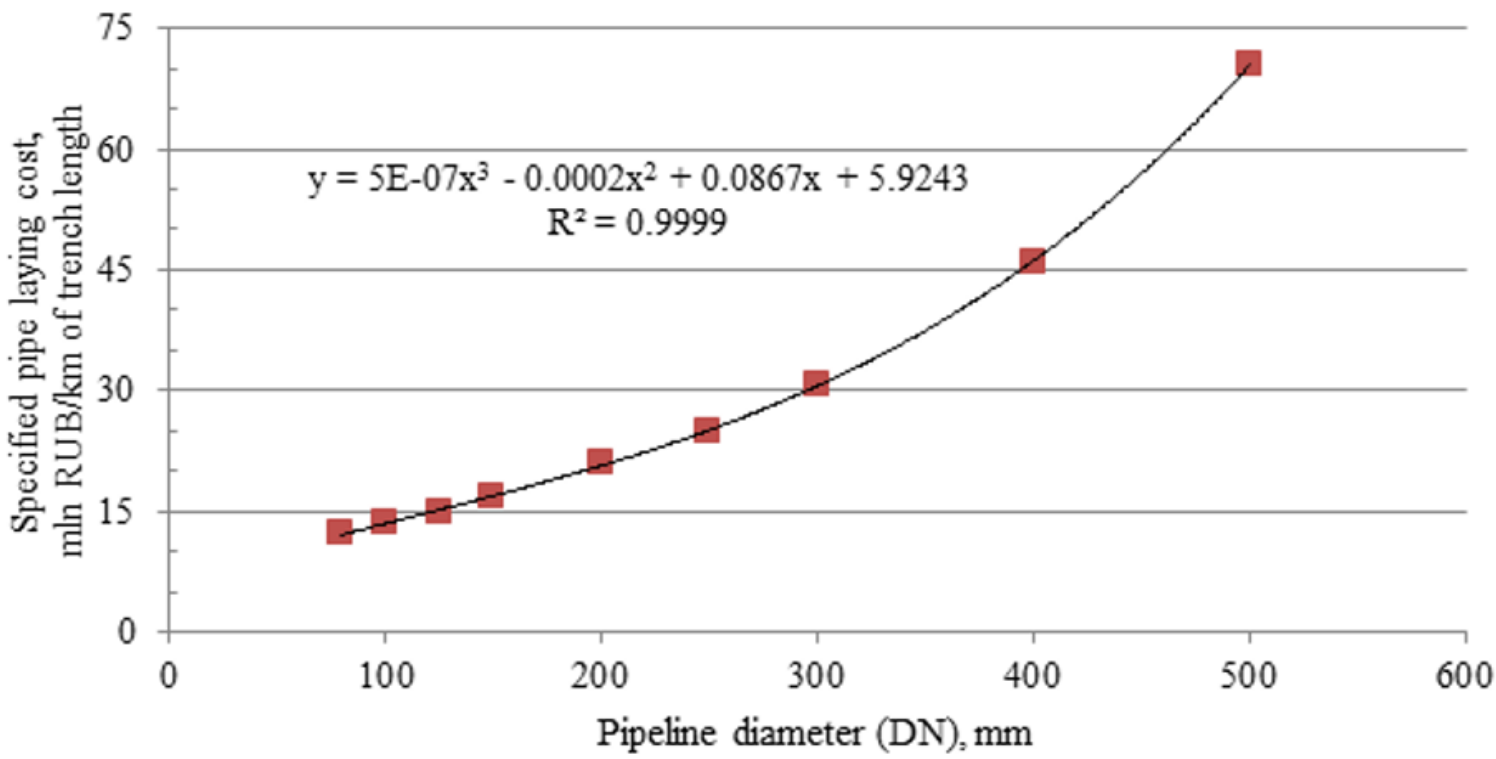

Fig. 4. Dependence of specified pipe laying costs from pipeline diameter.

$\frac{\partial \Delta N_{d v s p-t h d}}{\partial w_{I}}=\frac{21}{8} * K *\left(l_{l}+l_{l 3}\right) * w_{1}^{\frac{13}{8}} *\left(\left(V_{1}+V_{2}+\right.\right.$
$\left.\left.V_{3}\right)^{\frac{3}{8}}-V_{1}^{\frac{3}{8}}\right)$

$\frac{\partial \Delta N_{d v s p-t h d}}{\partial w_{H I}}=\frac{21}{8} * K * w_{11}^{\frac{13}{8}} *\left(\left(V_{2}+V_{3}\right)^{\frac{3}{8}} *\left(l_{l l}+l_{l l 3}\right)-\right.$
$\left.V_{2}^{\frac{3}{8}} *\left(l_{l}+l_{l 3}+l_{l l}+l_{l 13}\right)\right)$

$\frac{\partial \Delta N_{d v s p-t h d}}{\partial w_{m i}}=-\frac{21}{8} * K * V_{3}^{\frac{3}{8}} * w_{l 1}{ }^{\frac{13}{8}} *\left(l_{1}+l_{l 3}+l_{n}+\right.$ $\left.l_{n 13}\right)$

Formula (27) shows that the partial derivative $\frac{\partial \Delta N_{d v s p-t h d}}{\partial w_{l}}>0$, therefore increase of $w_{l}$ leads to increase of $\Delta N_{\text {dvsp-thd }}$. In this case, DVSP system becomes more energy consuming in comparison with THD-based system.

Formula (28) does not give unambiguous result, because the partial derivative $\frac{\partial \Delta N_{d v s p-t h d}}{\partial w_{H}}$ can be either higher than zero or less. This is defined by the multiplier in brackets.

Formula (29) shows that the partial derivative $\frac{\partial \Delta N_{d v s p-t h d}}{\partial w_{H i}}<0$, therefore increase of $w_{H I}$ leads to

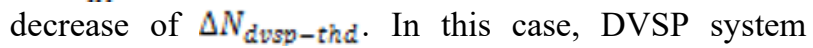
becomes less energy consuming in comparison with THD-based system.

\subsection{Economic analysis}

Total discounted costs of three systems were calculated in order to assess their feasibility [15]. Working lifespan of systems' equipment was assumed to be 10 years. Discount rate $=0.08$. Duration of heating period in Moscow is 205 days [16]. Electricity price is 6.1 $\mathrm{RUB} /\left(\mathrm{kW}^{*} \mathrm{hr}\right)$. Volume flow rate of every heat substation was assumed to be $70 \mathrm{~m}^{3} / \mathrm{hr}$ and pressure drop is $60 \mathrm{kPa}$. Pressure drop at heat source was assumed to be $200 \mathrm{kPa}$. The length of every main line (I, II, III) is 1 $\mathrm{km}$. Diameters of the main lines were chosen so that velocities in the main lines were almost the same for three systems. The prices of equipment were obtained from manufacturing companies. The cost of pipe laying was obtained from standardized costs of construction [17]. Trenchless pipe laying and polyurethane insulation were chosen for calculations (Figure 4).

\section{Results}

Figure 5 shows dependence of total discounted costs from velocity in the main line III. Velocities in the main lines I and II were $3.3 \mathrm{~m} / \mathrm{s}$. It can be seen that DVSP system has less total discounted costs than two other systems. This is also confirmed for the velocities in lines I and II less than $3.3 \mathrm{~m} / \mathrm{s}$. It turned out that the system with THD is quite expensive because of additional pipelines in this system. Therefore, it has high investment costs. DVSP system has minimum of total discounted costs when velocity in the line III is about 1.1 $\mathrm{m} / \mathrm{s}$.

Figure 6 shows dependence of total discounted costs of DVSP system from velocity in the main line III under different velocities in the lines I and II. The minimum of total discounted costs is still observed when velocity in the line III is about $1.1 \mathrm{~m} / \mathrm{s}$. As for velocities in the lines I and II, optimal value is $1.2 \mathrm{~m} / \mathrm{s}$. 


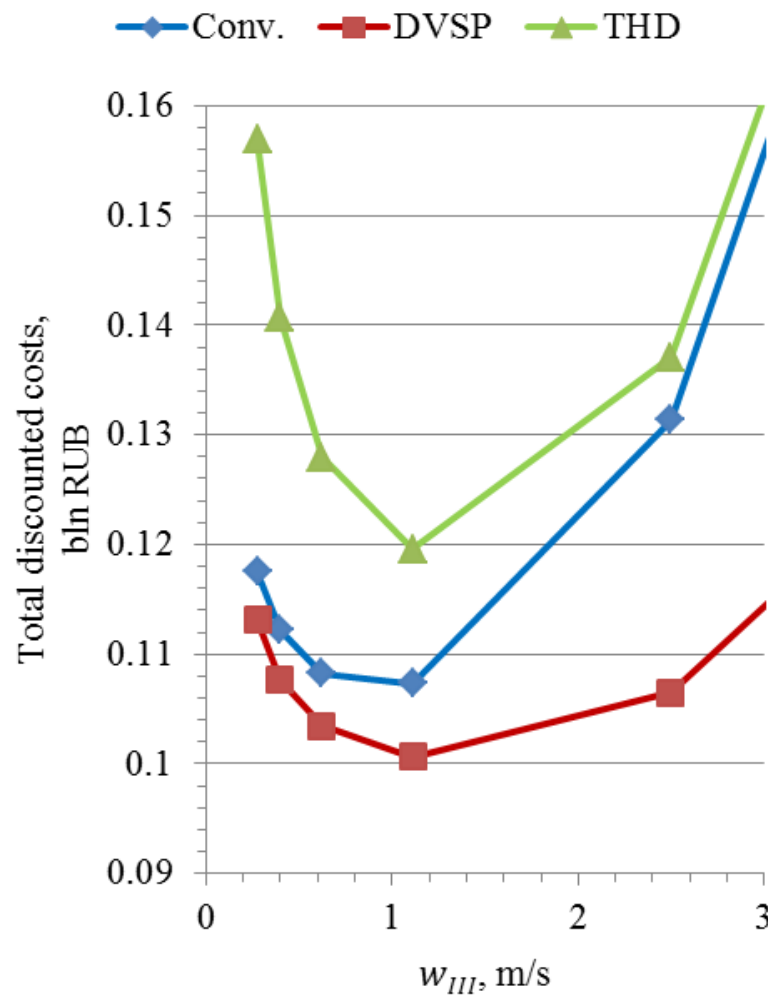

Fig. 5. Dependence of total discounted costs from velocity in the main line III.

$$
\begin{aligned}
& \multimap-3.3 \mathrm{~m} / \mathrm{s} \rightarrow-1.9 \mathrm{~m} / \mathrm{s} \longrightarrow-1.2 \mathrm{~m} / \mathrm{s} \\
& \leftarrow 0.8 \mathrm{~m} / \mathrm{s} \rightarrow 0.6 \mathrm{~m} / \mathrm{s}
\end{aligned}
$$

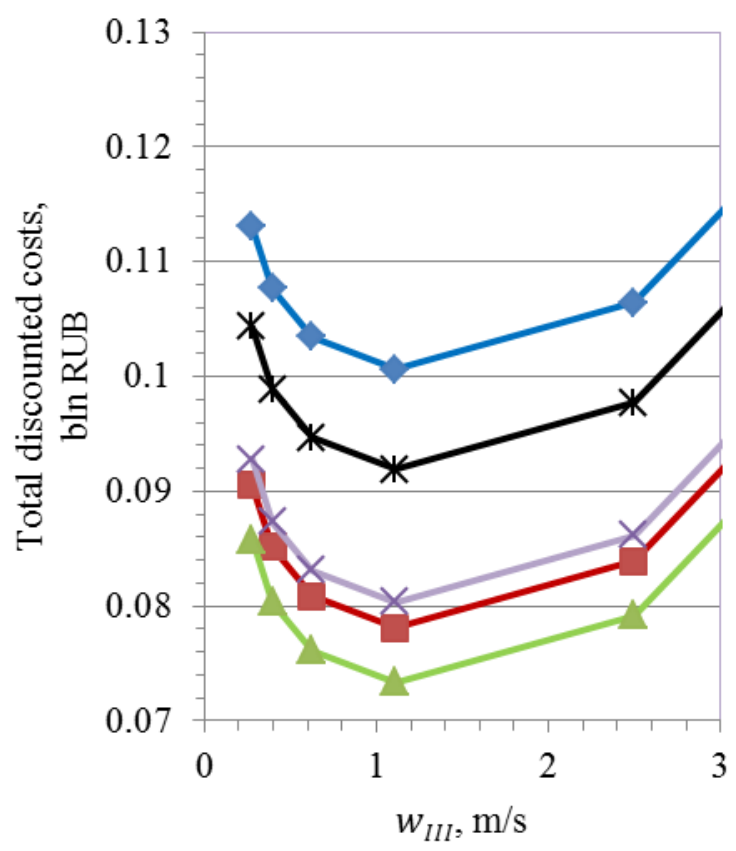

Fig. 6. Dependence of total discounted costs of DVSP system from velocity in the main line III under different velocities in the lines I and II.

\section{Discussion}

The obtained results show that for current economic situation in Russia DVSP system is more beneficial than conventional system or THD-based system. But this might change, if electricity price goes up or the cost of pipe laying goes down. So, these three systems should be considered and analysed before choosing the most rational system in particular technical and economic conditions. In some cases, combination of all three systems might be feasible solution. Similar approach is applied in [14].

Although both DVSP system and THD-based system allow for saving electricity comparing to conventional system, THD-based system has an additional advantage. The advantage is hydrodynamic separation of heat substations (consumers) from each other. If flow rate through a consumer changes, then the other consumers are not affected. On the contrary, DVSP system operation suggests that changing flow rate through a consumer makes the other consumers readjust their hydraulic regimes. This property of DVSP system was described in [12] and the algorithm of regulation was proposed. Nevertheless, regulation of DVSP system is harder due to large amount of distributed variable speed pumps needed to readjust every time hydraulic regime of any consumer changes. Additional pipelines in THDbased system might be considered as an advantage when it comes to heat supply network reliability questions. Therefore, other factors should be also taken into account to assess overall feasibility of the three systems

\section{Conclusion}

Three types of heat substation connection to heat source were considered in this paper. Power consumption calculations and economic analysis were performed. In result, DVSP system has less total discounted costs in comparison with conventional system and THD-based system. Conventional system is characterized by throttling of redundant hydraulic head and has higher electricity consumption which leads to higher operational costs. THD-based system has higher investment costs due to additional pipelines. DVSP system turns to be more beneficial but combination of the considered systems might be also feasible solution in some cases.

The work was performed under support of the state order № 13.9613.2017/8.9.

\section{References}

[1] Y.V. Yavorovsky, D.O. Romanov et al. Application of thermohydraulic dispatcher in low

temperature district heating systems for decreasing heat carrier transportation energy cost and increasing reliability of heat supply IOP Conf. Series: Journal of

Physics: Conf. Series 891 (2017)

[2] P.A. Khavanov Heat supply sources of autonomous systems (in Russian) (2014) 
[3] V.V. Sennikov, Y.V. Genvarev, et al. Application of thermohydraulic dispatcher in district

heating systems Vestnik IGEU 4, 27-30 (in Russian) (2009)

[4] V.V. Sennikov, Y.V. Genvarev, et al. Application of thermohydraulic dispatcher in heating substations of centralized heat supply system Vestnik IGEU 4, 15-20 (in Russian) (2012)

[5] D.O. Romanov, Y.V. Yavorovsky, et al. Experimental research of thermohydraulic dispatcher operating regimes Safety and Realiability of Power Industry 2, 106-112 (in Russian) (2019)

[6] Y.V. Yavorovsky, D.O. Romanov et al. Experimental research of thermo-hydraulic separators and dispatchers in heat supply systems Solid State Phenomena 284, 1385- 89 (2018)

[7] P.A. Khavanov, Autonomous heat supply sources with collectors of low differential pressure AVOK 3, 26-35 (in Russian) (2002)

[8] A. Yan, J. Zhao, et al Hydraulic performance of a new district heating systems with distributed variable speed pumps Applied Energy 112, 876-85 (2013)

[9] X. Sheng, and L. Duanmu, Electricity consumption and economic analyses of district

heating system with distributed variable speed pumps Energy and buildings 118, 291- 300 (2016)

[10] X. Sheng and L. Duanmu Energy saving analyses on the reconstruction project in district heating system with distributed variable speed pumps Applied Thermal Engineering 101, 432-45 (2016)

[11] X. Sheng and L. Duanmu Energy saving factors affecting analysis on district heating system with distributed variable frequency speed pumps Applied Thermal Engineering 121, 779-90 (2017)

[12] H. Wang, H. Wang, T. Zhu A new hydraulic regulation method on district heating system with distributed variable speed pumps Energy Conversion and

Management 147, 174-89 (2017)

[13] J. Zeng, J. Han, G. Zhang, Diameter optimization of district heating and cooling piping

network based on hourly load Applied Thermal

Engineering 107, 750-57 (2016)

[14] J. Gu, C. Qi, et al. Analysis of a hybrid control scheme in the district heating system with

distributed variable speed pumps Sustainable Cities and Society 48 (2019)

[15] N.D. Rogalev, A.G. Zubkova Economics of power industry (in Russian) (2005)

[16] Rules and regulations SP 131.13330.2012 Building climatology (in Russian)

[17] Aggregative standardized costs of construction operations. Heat supply network. NCS 8102- 13-2017 (in Russian) 